\title{
Use of a 4-week up-titration regimen of roflumilast in patients with severe COPD
}

This article was published in the following Dove Press journal: International Journal of COPD

\author{
Henrik Watz' \\ Nitin Bagul ${ }^{2}$ \\ Klaus F Rabe 3,4 \\ Stephen Rennard ${ }^{5,6}$ \\ Vijay KT Alagappan ${ }^{7}$ \\ Jonas Román ${ }^{8}$ \\ Axel Facius ${ }^{9}$ \\ Peter MA Calverley ${ }^{10}$ \\ 'Pulmonary Research Institute \\ at LungenClinic Grosshansdorf, \\ Airway Research Center North, \\ German Center for Lung Research, \\ Grosshansdorf, Germany; ${ }^{2}$ DNA \\ Medical Ltd, Langley, UK; ${ }^{3}$ Department \\ of Pulmonary Medicine, LungenClinic \\ Grosshansdorf, Airway Research \\ Center North, German Center \\ for Lung Research, Grosshansdorf, \\ ${ }^{4}$ Department of Medicine, Christian \\ Albrecht University Kiel, Kiel, \\ Germany; ${ }^{5}$ Department of Internal \\ Medicine, University of Nebraska \\ Medical Center, Omaha, NE, \\ USA; ${ }^{6}$ AstraZeneca, Cambridge, \\ UK; ${ }^{7}$ AstraZeneca, Gaithersburg, \\ MD, USA; ${ }^{8}$ AstraZeneca R\&D, \\ Gothenburg, Sweden; ' ${ }^{\text {thinkQ2 }}$ AG, \\ Baar, Switzerland; ${ }^{10}$ Department of \\ Clinical Sciences, Institute of Ageing \\ and Chronic Disease, University \\ of Liverpool, Liverpool, UK
}

\begin{abstract}
Background: The oral selective phosphodiesterase-4 inhibitor roflumilast (ROF) reduces exacerbations in patients with severe COPD. Adverse events (AEs) can cause early ROF discontinuation. Alternative dosing strategies may help patients continue their therapy.

Methods: In this multicenter, double-blind trial, 1,321 patients with severe COPD were randomized 1:1:1 to 4 weeks' treatment with ROF $250 \mu \mathrm{g}$ once daily (OD), $500 \mu \mathrm{g}$ every other day (EOD), or $500 \mu \mathrm{g}$ OD, each followed by ROF $500 \mu \mathrm{g}$ OD for 8 weeks, plus standard therapy. The primary end point was the percentage of patients prematurely discontinuing study treatment.

Results: Patients in the $250 \mu \mathrm{g} \mathrm{OD} / 500 \mu \mathrm{g}$ OD group had significantly fewer treatment discontinuations (odds ratio [OR] 0.66 [95\% CI 0.47-0.93], $p=0.017$ ) and lower rates of AEs of interest such as diarrhea, nausea, headache, decreased appetite, insomnia and abdominal pain (OR 0.63 [95\% CI 0.47-0.83], $p=0.001$ ) compared with those in the $500 \mu \mathrm{g}$ OD group. Although rates of discontinuation and AEs of interest were numerically lower with ROF $500 \mu \mathrm{g}$ EOD $/ 500 \mu \mathrm{g}$ OD, the difference was not significant (OR $0.76, p=0.114$, and OR $0.78, p=0.091$, respectively) compared with ROF $500 \mu \mathrm{g}$ OD.

Conclusion: A dose of ROF $250 \mu \mathrm{g}$ OD for 4 weeks before escalation to the approved maintenance dose of $500 \mu \mathrm{g}$ OD resulted in reduced treatment discontinuation and improved tolerability.
\end{abstract}

Keywords: roflumilast, COPD, discontinuation, adverse event

\section{Introduction}

Severe exacerbations of COPD are associated with a poor prognosis. ${ }^{1-3}$ Roflumilast (ROF) is a selective, oral phosphodiesterase-4 (PDE4) inhibitor used for the treatment of patients with severe COPD associated with chronic bronchitis and a history of exacerbations. ${ }^{4}$ Previous studies have shown that ROF as an add-on to inhaled COPD therapy reduces exacerbations in this patient population. ${ }^{5,6}$ More recently, this has been shown in the ROF and Exacerbations in patients receiving Appropriate Combination Therapy (REACT) study - in patients using ROF therapy in addition to an inhaled corticosteroid (ICS)/long-acting beta agonist (LABA) \pm long-acting muscarinic antagonist (LAMA) combination $^{7}-$ a finding most evident in those with a history of hospitalization. ${ }^{8}$

Patients initiating treatment with the approved $500 \mu \mathrm{g}$ dose of ROF may report side effects in the first few weeks, including diarrhea, nausea, headache, insomnia, abdominal pain, loss of appetite and a reduction in body weight. ${ }^{4,69}$ These are predominantly mild to moderate in severity and, with the exception of body weight reduction, typically transient - often resolving within the first few weeks of treatment. ${ }^{10}$ However, they are a common cause of early treatment discontinuation. Overall rates of discontinuations for patients taking $500 \mu \mathrm{g}$ of ROF in recent 52 -week clinical trials have been in the region of $30 \%,{ }^{7,11}$ although the rates of discontinuation are thought to be higher
Correspondence: Henrik Watz Pulmonary Research Institute at LungenClinic Grosshansdorf, Airway Research Center North, German Center for Lung Research, Woehrendamm 80, D-22927 Grosshansdorf, Germany Email h.watz@pulmoresearch.de (c) (1) (5) $\odot 218$ Watz et al. This work is published and licensed by Dove Medical Press Limited. The full terms of this license are available at https:///www.dovepress.com/terms.php (c) hereby accept the Terms. Non-commercial uses of the work are permitted without any further permission from Dove Medical Press Limited, provided the work is properly attributed. For permission for commercial use of this work, please see paragraphs 4.2 and 5 of our Terms (https://www.dovepress.com/terms.php). 
in clinical practice. ${ }^{12}$ Therefore, alternative dosing strategies to improve tolerability over the first few weeks of treatment may help patients continue their therapy.

The present study, referred to as OPTIMIZE (ClinicalTrials.gov: NCT02165826), investigated whether treatment discontinuation rates could be reduced and tolerability could be improved by using a reduced dose of ROF for a short initial treatment period. Phase I dose-ranging and modeling studies ${ }^{13}$ have previously suggested that a daily dose of $250 \mu \mathrm{g}$ is associated with an improved side effect profile compared with the approved $500 \mu \mathrm{g}$ dose. However, the $250 \mu \mathrm{g}$ dose is less efficacious, associated with less forced expiratory volume in 1 second $\left(\mathrm{FEV}_{1}\right)$ improvement, than the $500 \mu \mathrm{g}$ dose $^{14,15}$ and is not appropriate for long-term maintenance therapy.

The 12-week OPTIMIZE study evaluated the tolerability and discontinuation rate associated with a daily dose of $250 \mu \mathrm{g}$ ROF for the first 4 weeks, before escalation to $500 \mu \mathrm{g}$ for 8 weeks. In a parallel treatment arm, $500 \mu \mathrm{g}$ was given on alternate days for the first 4 weeks of treatment, before increasing to $500 \mu \mathrm{g}$ daily. The results of both up-titration strategies were compared with $500 \mu \mathrm{g}$ dose daily, taken continuously for 12 weeks. Pharmacokinetic analyses were undertaken to evaluate drug exposure in patients receiving the three treatment strategies to assess any correlation between drug exposure and ability to tolerate ROF.

\section{Methods}

\section{Patients}

Patients aged $\geq 40$ years with a history of COPD associated with chronic productive cough, $\geq 1$ moderate or severe exacerbation in the previous 12 months, and who were former/ current smokers (history of $\geq 10$ pack-years) were eligible for enrollment. A post-bronchodilator $\mathrm{FEV}_{1} \leq 50 \%$ of predicted and an $\mathrm{FEV}_{1}$ /forced vital capacity (FVC) ratio $<70 \%$ were required. Patients had to be receiving standard of care COPD treatment (LABA or LAMA or a combination of the two for at least 12 weeks). Patients were excluded if they had a COPD exacerbation ongoing at screening, a lower respiratory tract infection unresolved within 4 weeks prior to screening, asthma/other relevant lung disease, or known $\alpha 1$-antitrypsin deficiency (refer Supplementary materials for the full list of inclusion/exclusion criteria). ICS and theophylline were permitted if taken at a constant daily dose for 12 weeks prior. All patients involved in the OPTMIZE trial provided their written informed consent.

\section{Study design and interventions}

OPTIMIZE was a multicenter, double-blind, Phase III randomized trial conducted over 12 weeks, which included an initial 4-week up-titration period. All patients discontinuing the trial were offered the opportunity to enter an 8-week open-label down-titration phase, during which they received ROF $250 \mu \mathrm{g}$ OD (Figure S1).

Patients were randomized (by a computerized interactive voice response system/interactive web response system) to one of three treatment regimens (1:1:1) (Figure S1): ROF $250 \mu \mathrm{g}$ once daily (OD) for 4 weeks and then $500 \mu \mathrm{g}$ OD thereafter $(250 \mu \mathrm{g}$ OD/500 $\mu \mathrm{g}$ OD), ROF $500 \mu \mathrm{g}$ every other day (EOD) for 4 weeks and then $500 \mu \mathrm{g}$ OD thereafter (500 $\mu \mathrm{g}$ EOD/500 $\mu \mathrm{g}$ OD) or ROF $500 \mu \mathrm{g}$ OD for 12 weeks $(500 \mu \mathrm{g}$ OD). Patients continued receiving their usual maintenance therapy.

The first 4 weeks (up-titration) of the trial were double blinded, and the remaining 8 weeks (maintenance period) were single blinded, with only the sponsor and investigators aware that the patient was receiving ROF $500 \mu \mathrm{g}$ OD. The original randomized treatment regimen remained blinded to all parties involved in the study for the duration of the study. ROF 250 and $500 \mu \mathrm{g}$ and placebo were supplied as identical white, round, biplane tablets in wallet cards containing 20 tablets, with identical labeling and packaging.

Patients attended clinics at screening, randomization and Weeks 2, 4, 8 and 12. Those discontinuing and entering the down-titration phase also attended clinic on Weeks 2, 4 and 8 of the down-titration. Study medication was accounted for at each visit to assess compliance.

The study protocol was approved by each respective institutional review board and followed established good clinical practice guidelines. A list of all approving institutional review boards is available in Table S1. All patients gave written informed consent for this study.

\section{Outcomes and end points}

The primary end point was the percentage of patients prematurely discontinuing study treatment for any reason during the 12-week study period. Secondary end points included the percentage of patients with adverse events (AEs) of interest (diarrhea, nausea, headache, decreased appetite, insomnia and abdominal pain) during the trial, percentage of patients prematurely discontinuing study treatment for any reason during the down-titration phase, and change in pre-bronchodilator $\mathrm{FEV}_{1}$ during both the trial and the down-titration phase. The six types of AEs of interest used to evaluate tolerability were selected as they are the most common AEs associated with ROF treatment, the main reason for treatment discontinuation, and assumed to be related to PDE4 inhibition.

Safety assessments included monitoring AEs and assessment of Columbia-Suicide Severity Rating Scale (C-SSRS), 
body weight, and body mass index (BMI). AEs of interest (occurrence and intensity) were assessed on a daily basis using diary cards. Intensity (mild/moderate/severe) was evaluated using a 7-point Likert scale.

\section{Pharmacokinetic evaluations}

Pharmacokinetics (PK) of ROF and ROF $N$-oxide were measured using $6 \mathrm{~mL}$ blood samples by Pharmaceutical Product Development (Middleton, WI, USA) using a high-performance liquid chromatography tandem mass spectrometer, as described previously. ${ }^{16}$

An integrated population PK (popPK) model was developed to predict individual $\mathrm{ROF} / \mathrm{ROF} N$-oxide exposure levels and total PDE4 inhibitory activity (tPDE4i) levels and assess whether patients unable to tolerate ROF $500 \mu \mathrm{g}$ OD have drug exposure with $250 \mu \mathrm{g}$ OD, similar to patients on a $500 \mu \mathrm{g}$ OD dose. The integrated popPK model was developed from an earlier base model in which the structural parameters were fixed to estimates from a dataset of 21 Phase I and two Phase II/III studies. ${ }^{16}$ This base model used combined REACT/OPTIMIZE datasets. ${ }^{7,17}$

\section{Statistical analyses}

A hierarchical testing approach was followed; if significance $(5 \%)$ was not reached, subsequent tests were exploratory. The hierarchy of testing for the null hypothesis was first: if the percentage of patient discontinuations on ROF $250 \mu \mathrm{g}$ $\mathrm{OD} / 500 \mu \mathrm{g}$ were not lower than or equal to that on ROF $500 \mu \mathrm{g}$ OD by Week 12, then the percentage of patient discontinuations on ROF $500 \mu \mathrm{g}$ EOD/500 $\mu \mathrm{g}$ OD were not lower than or equal to that on ROF $500 \mu \mathrm{g}$ OD by Week 12 (refer Supplementary materials for full list).

The primary end point and secondary safety end points were based on the safety analysis set (SAS) and performed using a logistic regression model. For the primary end point and AEs of interest, the treatment odds ratio (OR) and relative risk (RR) between groups ${ }^{18}$ were calculated. The secondary efficacy end point, change in pre-bronchodilator $\mathrm{FEV}_{1}$, was based on the full analysis set (FAS) and analyzed using an analysis of covariance model.

Additional post hoc exploratory analyses were undertaken to further assess whether weight loss on ROF was related to, 1) baseline BMI, and 2) gastrointestinal AEs and/or decreased appetite (no formal statistical testing performed).

For calculation of sample size, rates of discontinuation for any reason were estimated based on pooled data from the ROF COPD pivotal studies, ${ }^{6,9}$ which included a similar patient population to the OPTIMIZE study. Assuming a discontinuation rate of $20 \%$ with ROF $500 \mu \mathrm{g}$ OD and $13 \%$ with either up-titration regimen, a total of 441 patients per treatment arm, 1,323 overall, would provide $80 \%$ power to declare superiority of each of ROF $250 \mu \mathrm{g}$ OD/500 $\mu \mathrm{g}$ OD and ROF $500 \mu \mathrm{g}$ EOD/500 $\mu \mathrm{g}$ OD versus ROF $500 \mu \mathrm{g}$ OD for 12 weeks.

\section{Results}

\section{Patients}

The study was conducted at 161 sites across 15 countries (refer Supplementary materials for full list) between April 2014 and October 2015. In total, 1,323 patients were randomized, of whom 1,321 received treatment. A total of 104 patients entered the down-titration phase (Figure 1). Data presented hereafter are for the 12-week trial population; data on the down-titration phase are included in the Supplementary materials.

Baseline characteristics were generally balanced across the treatment arms (Table 1). Patients had a mean age of 64.6 years and were predominantly male (74.4\%). Compliance with study medication ranged from $101 \%$ to $104 \%$ across treatment arms. Demographic and baseline characteristics of patients who entered the down-titration phase are presented in Table S2.

\section{Study discontinuations}

The greatest between-group difference in discontinuations occurred in the first few weeks of treatment (Figure 2A). Significantly fewer patients discontinued treatment (for any reason) in the ROF $250 \mu \mathrm{g} \mathrm{OD} / 500 \mu \mathrm{g}$ OD group compared with the ROF $500 \mu \mathrm{g}$ OD group (18.4\% versus $24.6 \%$; RR 0.72 [95\% CI 0.54-0.95], OR 0.66 [95\% CI 0.47-0.93], $p=0.017$; Figure 2B). There were fewer treatment discontinuations in the ROF $500 \mu \mathrm{g}$ EOD/500 $\mu \mathrm{g}$ OD group compared with the ROF $500 \mu \mathrm{g}$ OD group, but this difference did not reach statistical significance $(20.1 \%$ versus $24.6 \%$; RR 0.81 [95\% CI 0.62-1.05], OR 0.76 [95\% CI 0.55-1.07], $p=0.114$; Figure 2). Based on the hierarchical testing approach, all interpretations of $p$-values after the second hierarchical test are exploratory.

\section{Tolerability}

Significantly fewer patients experienced AEs of interest in the ROF $250 \mu \mathrm{g}$ OD/500 $\mu \mathrm{g}$ OD arm compared with the ROF $500 \mu \mathrm{g}$ OD arm (45.4\% versus 54.2\%; RR 0.79 [95\% CI 0.66-0.91], OR 0.63 [95\% CI 0.47-0.83], $p=0.001$; Figure 3). The frequency of all AEs of interest was lower, and the median time to onset was longer in the ROF $250 \mu \mathrm{g}$ OD/500 $\mu \mathrm{g}$ OD arm compared with the ROF $500 \mu \mathrm{g}$ OD arm (Table S3). The proportion of patients reporting AEs of interest was numerically lower in the ROF $500 \mu \mathrm{g}$ $\mathrm{EOD} / 500 \mu \mathrm{g}$ OD arm compared with the $500 \mu \mathrm{g}$ OD arm, but 


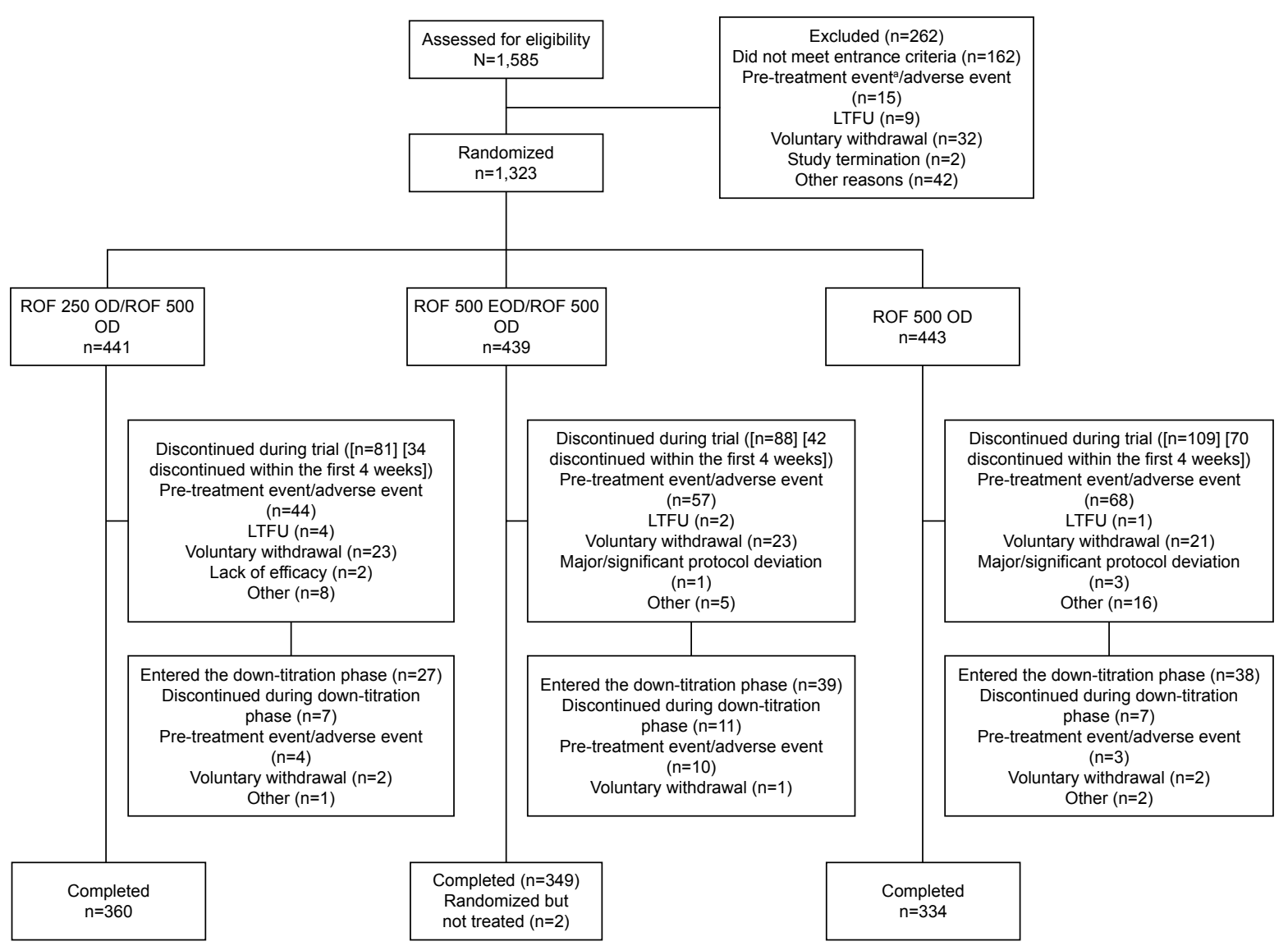

Figure I Patient disposition.

Notes: ${ }^{a} \mathrm{~A}$ pre-treatment event is defined as any untoward medical occurrence in a patient who had signed written informed consent to participate in a study, but prior to administration of any study medication; it did not necessarily have to have a causal relationship with study participation.

Abbreviations: EOD, every other day; LTFU, lost to follow-up; OD, once daily; ROF, roflumilast; $250,250 \mu \mathrm{g} ; 500,500 \mu \mathrm{g}$.

Table I Baseline patient characteristics

\begin{tabular}{|c|c|c|c|}
\hline Characteristics & $\begin{array}{l}\text { ROF } 250 \text { OD/ROF } \\
500 \text { OD }(n=44 I)\end{array}$ & $\begin{array}{l}\text { ROF } 500 \text { EOD/ROF } \\
500 \text { OD }(n=437)\end{array}$ & $\begin{array}{l}\text { ROF } 500 \\
\text { OD }(n=443)\end{array}$ \\
\hline Age, years & $64.2(7.8)$ & $65.0(8.2)$ & $64.6(8.4)$ \\
\hline Male, n (\%) & $320(72.6)$ & $325(74.4)$ & $338(76.3)$ \\
\hline White, $\mathrm{n}(\%)$ & 405 (9l.8) & $399(91.3)$ & $405(91.4)$ \\
\hline BMI, kg/m² & $26.4(6.0)$ & $26.01(5.6)$ & $26.46(5.9)$ \\
\hline Cigarette pack years & $38.1(17.5)$ & $40.2(19.2)$ & $37.6(17.7)$ \\
\hline Current smoker, n (\%) & $213(48.3)$ & $198(45.3)$ & $196(44.2)$ \\
\hline Pre-bronchodilator $\mathrm{FEV}_{1}$, L & $\mathrm{I} .0(0.3)$ & $\mathrm{I} .0(0.3)$ & $1.0(0.3)$ \\
\hline Pre-bronchodilator FVC, L & $2.3(0.7)$ & $2.3(0.7)$ & $2.3(0.7)$ \\
\hline$\%$ predicted $\mathrm{FEV}$, & $36.0(8.8)$ & $36.7(8.8)$ & $36.0(9.5)$ \\
\hline Post-bronchodilator $\mathrm{FEV}_{\mathrm{I}} / \mathrm{FVC}$ & $0.46(0.1)$ & $0.47(0.1)$ & $0.46(0.1)$ \\
\hline$\% \mathrm{FEV}_{\text {, }}$ reversibility & $7.1(12.0)$ & $6.45(14.4)$ & $7.4(1 \mathrm{I} .4)$ \\
\hline$\leq 2$ exacerbations, $\mathrm{n}(\%)$ & $435(98.6)$ & $427(97.7)$ & $432(97.5)$ \\
\hline$>2$ exacerbations, $\mathrm{n}(\%)$ & $6(1.4)$ & $9(2.1)$ & $9(2.0)$ \\
\hline $\begin{array}{l}\text { Most commonly reported } \\
\text { concomitant medication, } \mathrm{n}(\%)^{\mathrm{a}}\end{array}$ & $440(99.8)$ & $437(100.0)$ & $443(100.0)$ \\
\hline LAMA (tiotropium bromide) & $245(55.6)$ & $235(53.8)$ & $225(50.8)$ \\
\hline ICS/LABA (seretide, budesonide) & $202(45.8)$ & $197(45.0)$ & $217(48.9)$ \\
\hline Theophylline & $80(18.1)$ & 85 (19.5) & $80(18.1)$ \\
\hline
\end{tabular}

Notes: Data are taken from the SAS and expressed as mean (SD) unless otherwise stated. ${ }^{\text {TTaken }}$ in $\geq 10 \%$ of all patients.

Abbreviations: BMI, body mass index; EOD, every other day; $\mathrm{FEV}_{1}$, forced expiratory volume in I second; FVC, forced vital capacity; ICS, inhaled corticosteroid; LABA, long-acting beta agonist; LAMA, long-acting muscarinic antagonist; OD, once daily; ROF, roflumilast; SAS, safety analysis set; SD, standard deviation; $250,250 \mu \mathrm{g}$; $500,500 \mu \mathrm{g}$. 
A

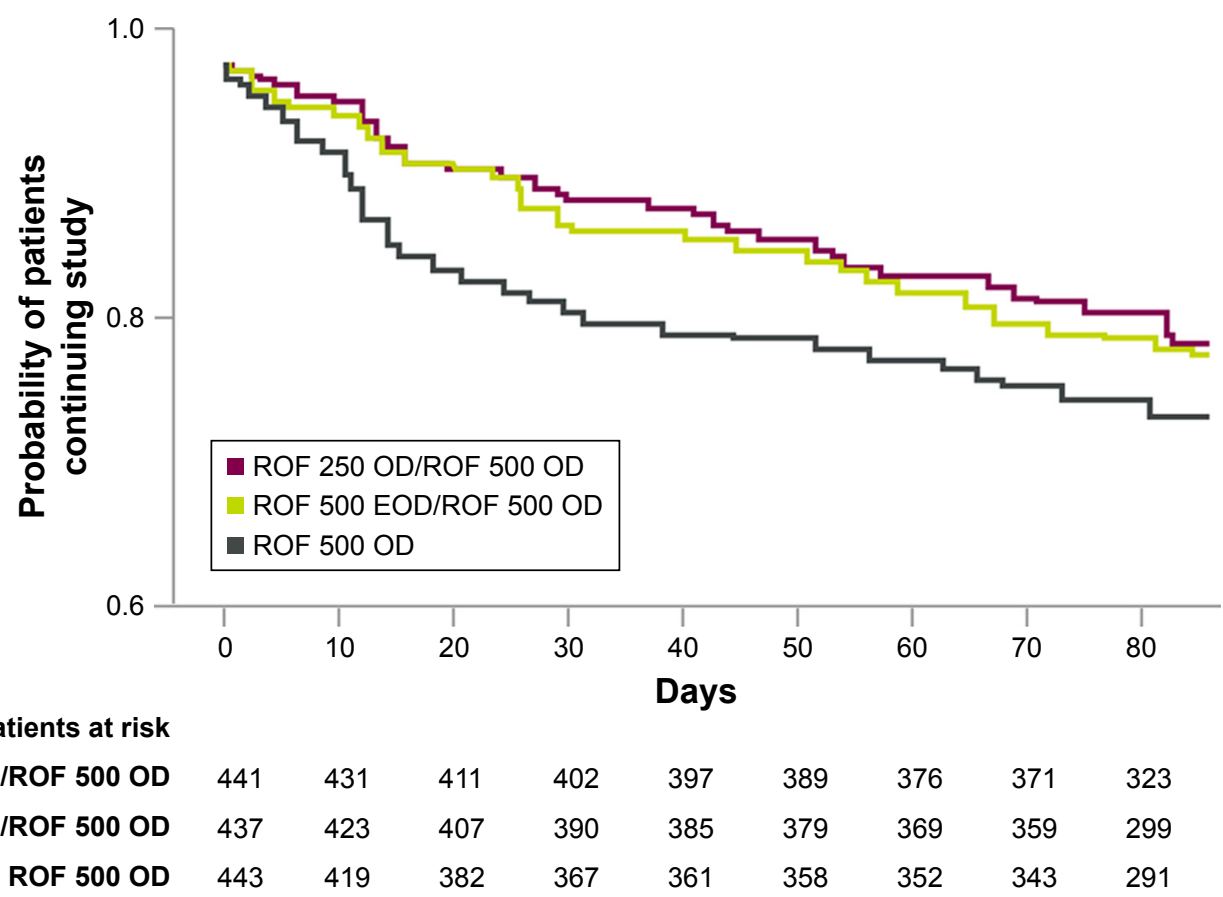

B

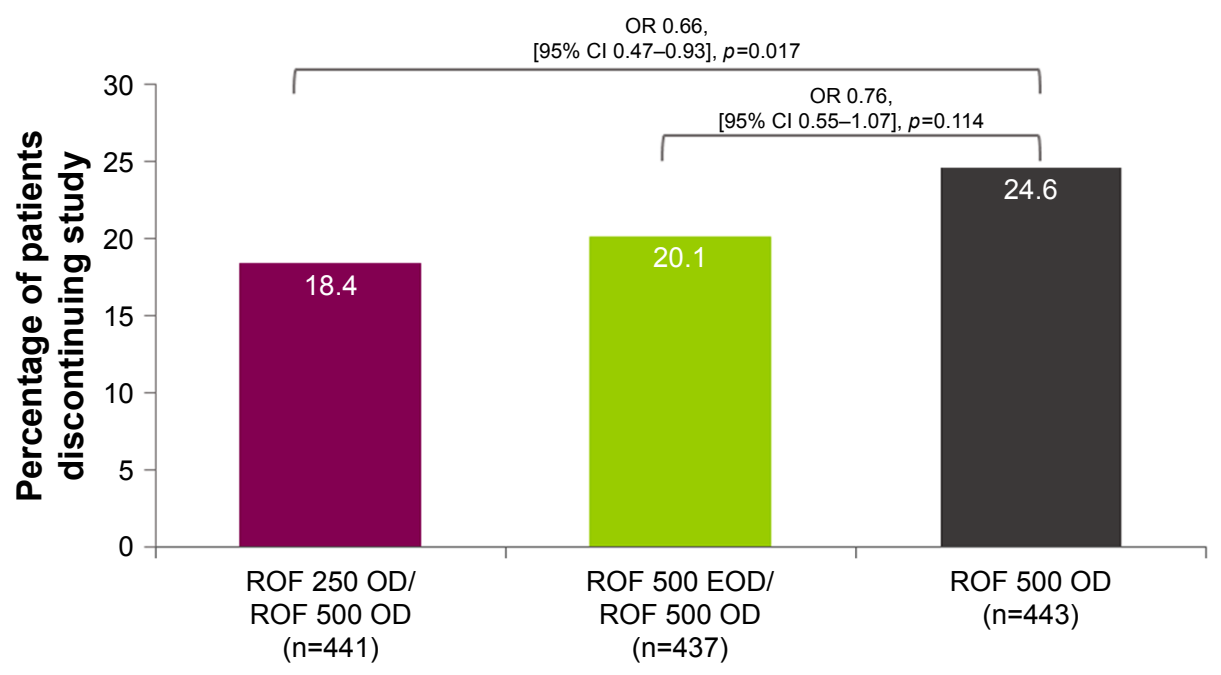

Figure 2 (A) Probability of patients continuing the 12-week trial for any reason (SAS). (B) Percentage of patients discontinuing for any reason.

Abbreviations: $\mathrm{Cl}$, confidence interval; $\mathrm{EOD}$, every other day; OD, once daily; OR, odds ratio; ROF, roflumilast; $\mathrm{SAS}$, safety analysis set; $250,250 \mu \mathrm{g} ; 500,500 \mu \mathrm{g}$.

the difference was not significant (48.3\% versus $54.2 \%$; OR 0.78 [95\% CI 0.59-1.04, $p=0.091]$ ); (Figure 3 and Table S3). The AEs of interest were predominantly mild or moderate (Table S4) and of short duration (2-4 days; data include discontinued patients; Table S3). For each treatment arm, among patients who discontinued, the most commonly reported $\mathrm{AE}$ of interest was diarrhea $(19.8 \%, 31.8 \%$, and $33 \%$, in the ROF $250 \mu \mathrm{g} \mathrm{OD} / 500 \mu \mathrm{g}$ OD, $500 \mu \mathrm{g}$ EOD/500 $\mu \mathrm{g}$ OD and the $500 \mu \mathrm{g}$ OD arms respectively; Table S5).

The percentage of patients who withdrew from treatment due to AEs was $13.2 \%, 15.3 \%$, and $17.4 \%$ with ROF $250 \mu \mathrm{g}$
$\mathrm{OD} / 500 \mu \mathrm{g}$ OD, $500 \mu \mathrm{g} \mathrm{EOD} / 500 \mu \mathrm{g} \mathrm{OD}$, and $500 \mu \mathrm{g} \mathrm{OD}$, respectively. AEs that most commonly led to discontinuation in the ROF $250 \mu \mathrm{g}$ OD $/ 500 \mu \mathrm{g}$ OD arm, $500 \mu \mathrm{g}$ EOD $/ 500 \mu \mathrm{g}$ OD arm, and $500 \mu \mathrm{g}$ OD arm, were diarrhea (3.6\%, 6.4\%, and $8.1 \%$ of patients, respectively), decreased appetite (3.6\%, $4.6 \%$, and $7.4 \%$ of patients, respectively), and nausea (3.9\%, 3.7\%, $6.1 \%$ of patients, respectively).

Overall, $63.7 \%$ of patients experienced any AE: $61.2 \%$, $64.3 \%$, and $65.7 \%$ with ROF $250 \mu \mathrm{g}$ OD/500 $\mu \mathrm{g}$ OD, $500 \mu \mathrm{g} \mathrm{EOD} / 500 \mu \mathrm{g}$ OD, and $500 \mu \mathrm{g}$ OD, respectively. The most frequently reported AEs were those assessed as AEs 


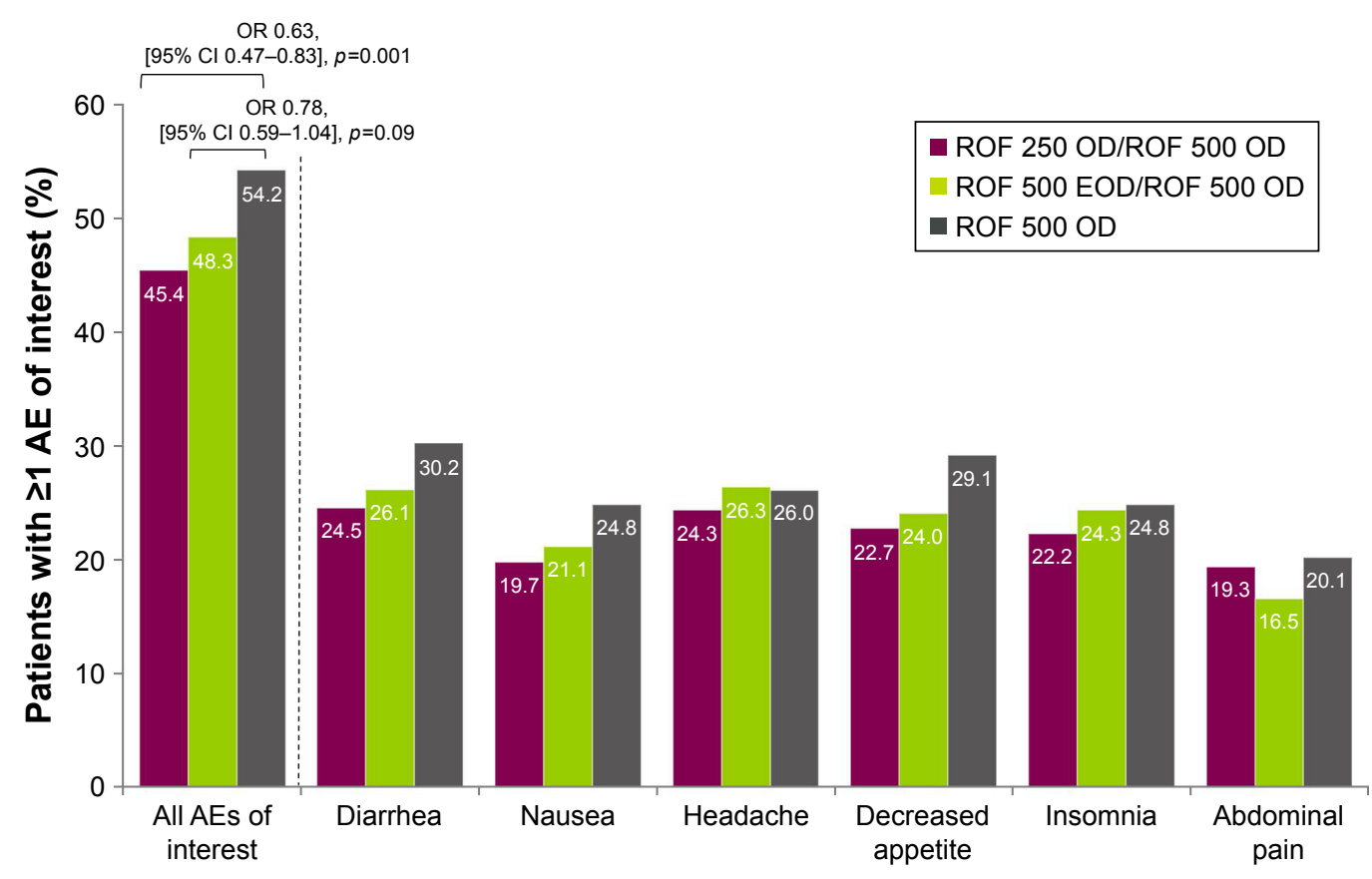

Figure 3 Summary of AEs of interest.

Note: Percentage of patients with $\geq I A E$ to evaluate tolerability.

Abbreviations: $\mathrm{AE}$, adverse event; $\mathrm{Cl}$, confidence interval; $\mathrm{EOD}$, every other day; OD, once daily; OR, odds ratio; ROF, roflumilast; $250,250 \mu \mathrm{g} ; 500,500 \mu \mathrm{g}$.

of interest. During the trial, $4.6 \%$ of patients experienced a serious $\mathrm{AE}$ and six deaths were reported (three in the $250 \mu \mathrm{g}$ OD/500 $\mu \mathrm{g}$ OD arm [COPD, cardiac failure, and cardiopulmonary failure], one in the $500 \mu \mathrm{g} \mathrm{EOD} / 500 \mu \mathrm{g}$ OD arm [pneumothorax spontaneous], and two in the $500 \mu \mathrm{g}$ OD arm [lung adenocarcinoma and myocardial infarction]). Suicidal ideation was reported in one patient in the ROF $500 \mu \mathrm{g}$ OD group during the trial, and this patient discontinued treatment as a result.
Weight decrease was self-reported by $2.3 \%, 2.1 \%$, and $3.8 \%$ of patients who received $250 \mu \mathrm{g}$ OD/500 $\mu \mathrm{g}$ OD, $500 \mu \mathrm{g}$ EOD/500 $\mu \mathrm{g}$ OD, and $500 \mu \mathrm{g}$ OD, respectively. Reduction in body weight was evident from Week 2 and was of a similar magnitude across treatment groups (mean decrease 1.02, 0.82, and $0.98 \mathrm{~kg}$, respectively; Figure 4). In post hoc analyses, weight loss tended to be greater in patients with a BMI $>25 \mathrm{~kg} / \mathrm{m}^{2}$ compared with those with a BMI $\leq 25 \mathrm{~kg} / \mathrm{m}^{2}$ in all treatment groups (Table S6).

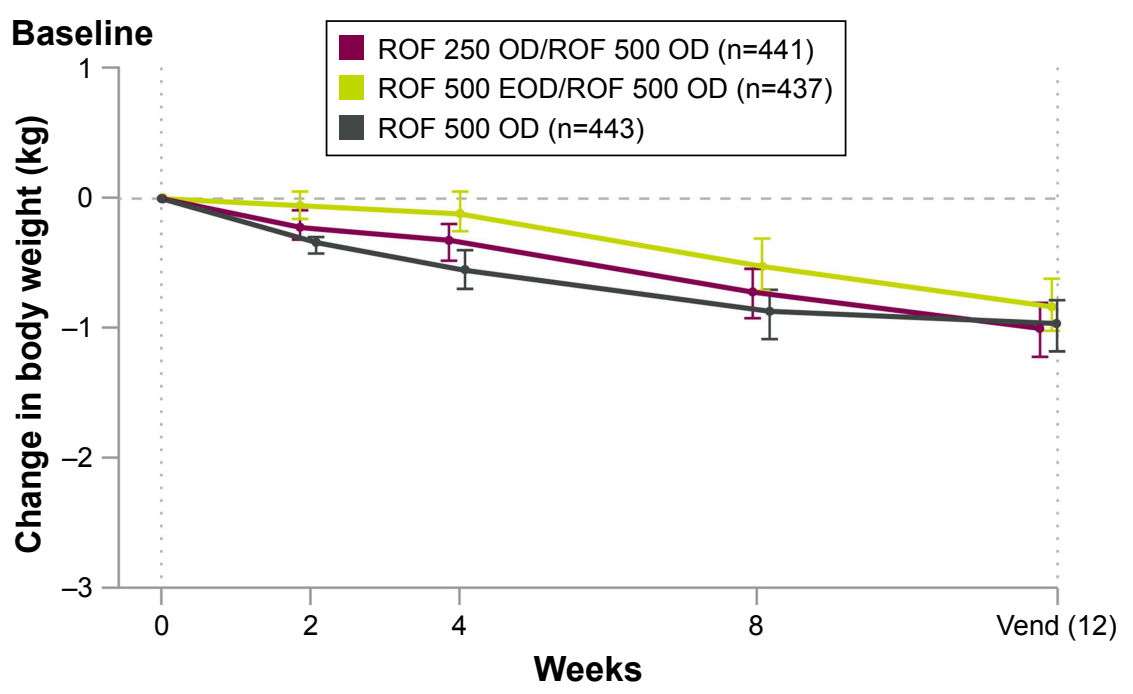

Figure 4 Mean change in body weight.

Notes: Measurements are mean, with bars showing SD. Vend was the last measurement obtained before dropout/study completion.

Abbreviations: EOD, every other day; OD, once daily; ROF, roflumilast; SD, standard deviation; $250,250 \mu \mathrm{g} ; 500,500 \mu \mathrm{g}$. 


\section{Lung function}

Improvements from baseline in pre-bronchodilator $\mathrm{FEV}_{1}$ over the trial were minimally different between ROF $250 \mu \mathrm{g}$ OD/500 $\mu \mathrm{g}$ OD, $500 \mu \mathrm{g}$ EOD/500 $\mu \mathrm{g}$ OD, and $500 \mu \mathrm{g}$ OD treatment groups (least squares [LS] mean change 90, 130, and $110 \mathrm{~mL}$, respectively).

\section{Pharmacokinetics}

Individual PK parameters and tPDE4i values were derived for 1,238 patients with at least one quantifiable PK sample, ${ }^{17}$ including 101 patients who discontinued the 12-week trial and entered the down-titration phase, of whom 76 entered after not tolerating at least one dose of ROF $500 \mu \mathrm{g}$. Patients who discontinued ROF $500 \mu \mathrm{g}$ OD in the trial because of AEs of interest had a slightly higher median tPDE4i $(>10 \%)$ than those able to tolerate this dose (median tPDE4i level: 1.28 and 1.16, respectively; Figure 5). However, as expected with linear PK, reducing the dose to $250 \mu \mathrm{g}$ OD in these patients reduced tPDE4i to below that typically observed in patients able to tolerate the $500 \mu \mathrm{g}$ OD (median tPDE4i level: 0.65).

\section{Discussion}

Although the side effects that may occur soon after initiation of ROF are often transient in nature and predominantly mild to moderate in severity, they are a common reason for discontinuing treatment. Using an alternative reduced dosing regimen for a short initial treatment period (as used successfully with other systemic therapies) $)^{19-22}$ is one strategy to help increase the acceptability of ROF treatment and help patients stay on therapy. The OPTIMIZE study supports this concept. While use of a reduced dose of ROF as long-term maintenance therapy may not induce sufficient PDE4 inhibition to exert the clinical efficacy of the $500 \mu \mathrm{g}$ dose,,$^{14,15}$ it can be used as part of an up-titration regimen to overcome tolerability issues in the first weeks of treatment and hence reduce discontinuation rates.

Initiating ROF at a $250 \mu \mathrm{g}$ daily dose for 4 weeks, before escalating to $500 \mu \mathrm{g}$ daily dose for 8 weeks, was associated with a statistically significant decrease in the percentage of patients discontinuing treatment for any reason and reporting side effects of interest. The overall discontinuation rate for

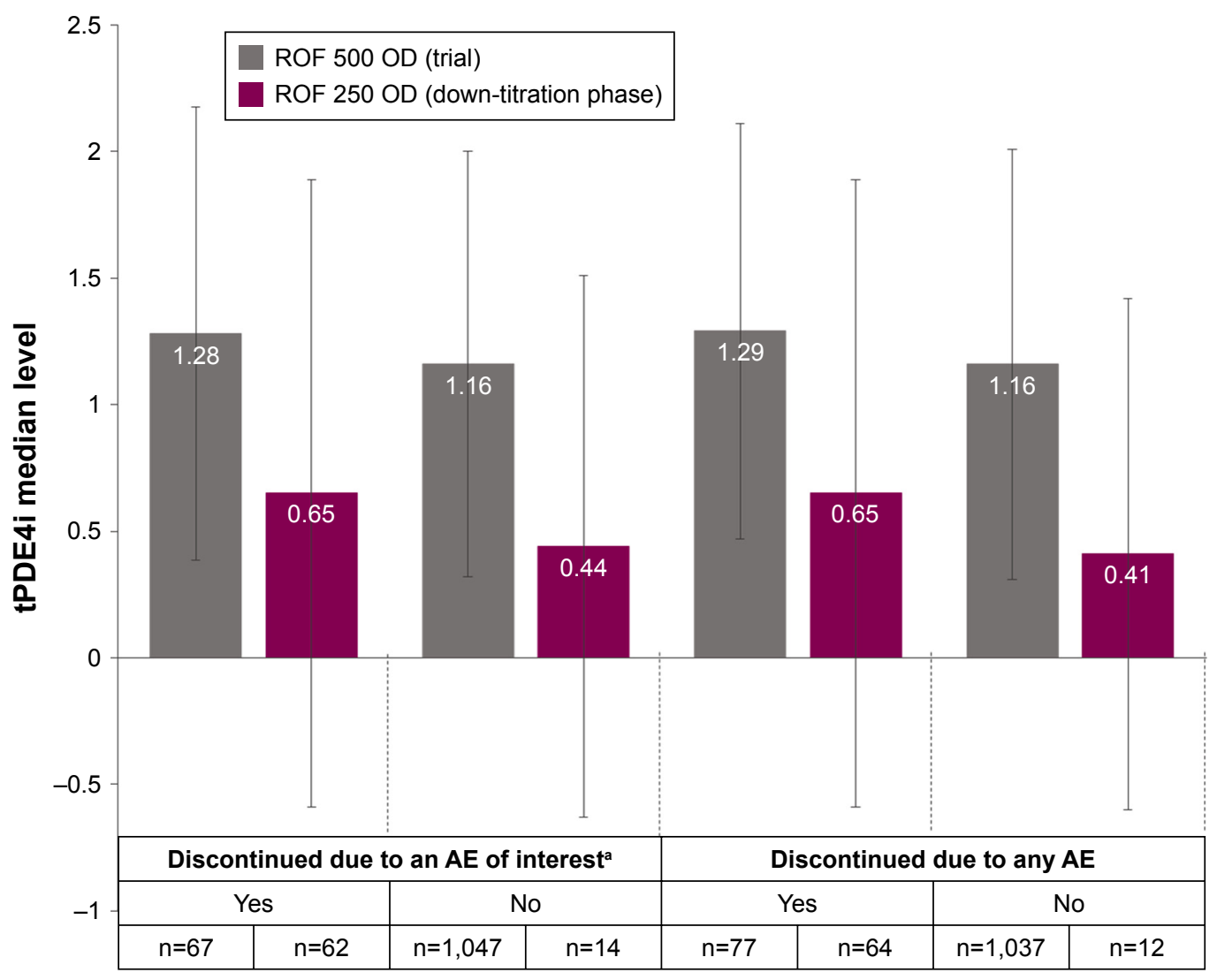

Figure 5 Comparison of tPDE4i levels achieved with ROF $500 \mu \mathrm{g}$ or $250 \mu \mathrm{g}$ according to whether patients were able to tolerate the dose.

Notes: Medians in trial and down-titration phase. ${ }^{\mathrm{a}}$ For consistency with previous popPK models, the list of preferred terms included in the AEs of interest for the popPK model is larger than that used to investigate safety in this study (Table S7). Error bars are $95 \% \mathrm{Cl}$.

Abbreviations: $\mathrm{AE}$, adverse event; $\mathrm{Cl}$, confidence interval; OD, once daily; popPK, population pharmacokinetics; ROF, roflumilast; tPDE4i, total phosphodiesterase-4 inhibitory activity; 250, $250 \mu \mathrm{g} ; 500,500 \mu \mathrm{g}$. 
patients taking ROF $500 \mu \mathrm{g}$ daily in the current study was in line with that observed in recent ROF clinical trials, ${ }^{7,11}$ and for patients starting at the reduced dosing of $250 \mu \mathrm{g}$ daily, the odds of early discontinuation and experiencing side effects of interest were $34 \%$ and $37 \%$ lower (RR reduction $28 \%$ and $21 \%$ ). Patients starting ROF at $500 \mu \mathrm{g}$ on alternate days also reported fewer side effects and lower treatment discontinuation rates, but this was not significantly different compared with the $500 \mu \mathrm{g}$ daily regimen.

The AEs of interest selected as a focus for OPTIMIZE study have previously been identified as limiting tolerability to ROF.,6,9 Diarrhea and other gastrointestinal side effects particularly, have been perceived as a barrier to ROF treatment. Diarrhea accounted for approximately one-third of discontinuations with the $500 \mu \mathrm{g}$ dose, and this was lowered to approximately $20 \%$ with reduced dosing.

The mechanisms by which ROF causes nausea and diarrhea are believed to be distinct. Nausea is mediated by PDE4-D; located outside the blood-brain barrier, this subtype is accessible to ROF. ${ }^{23}$ The mechanism behind diarrhea is less clear; activators of the cystic fibrosis transmembrane conductance regulator (CFTR) are known to be potent inducers of diarrhea, and it is thought that PDE4 inhibition could activate this mechanism. ${ }^{24,25}$

Weight loss is a known systemic side effect of $\mathrm{ROF}^{6,9}$ and has been reported with both selective and nonselective PDE inhibitors. ${ }^{26}$ However, it did not appear to be a significant reason for discontinuation in OPTIMIZE, accounting for $<1 \%$ of discontinuations overall. Reductions in body weight were similar between all three dosing regimens and comparable with previous studies when treatment length is taken into account. ${ }^{6,9}$ Absolute weight loss tended to be more pronounced in patients with a higher baseline BMI and in those who also experienced gastrointestinal side effects or loss of appetite with ROF (as seen previously). ${ }^{6}$ While the mechanism by which ROF causes weight decrease remains to be fully elucidated, it is thought to be related to the effects of increased cAMP on signaling pathways regulating lipolysis. ${ }^{15}$

Frequency of individual side effects of interest was always lowest in the $250 \mu \mathrm{g} / 500 \mu \mathrm{g}$ OD group followed by the $500 \mu \mathrm{g}$ EOD/500 $\mu \mathrm{g}$ OD group and then the $500 \mu \mathrm{g}$ OD group. One exception was abdominal pain; the reason for this was unclear. Frequencies of some side effects of interest were higher in this study than those reported in previous studies; ${ }^{7,11}$ one explanation for this finding may be that OPTIMIZE, in contrast to previous studies, used a daily patient-assessed diary method to record side effects of interest. As OPTIMIZE did not include a placebo arm, the impact of the use of daily diary cards on side effect rates cannot be assessed. Additionally, levels of theophylline were not known in the 80 patients who were taking it, but may have contributed to increased reporting of side effects in these patients.

The $250 \mu \mathrm{g}$ daily dose was selected as the appropriate reduced dose following modeling studies, suggesting an improved side effect profile, compared with the $500 \mu \mathrm{g}$ maintenance dose. ${ }^{13}$ Lung function measurements in OPTIMIZE revealed that the initial 4-week up-titration regimens did not appear to reduce the effect of the drug on lung function. $\mathrm{FEV}_{1}$ improvements of $\sim 100 \mathrm{~mL}$ in all treatment arms were observed; this improvement is at the upper range of changes compared with previous studies. , $^{6,9,11}$

Following oral dosing, ROF is rapidly converted by cytochrome $\mathrm{P} 450$ enzymes to its active metabolite ROF $N$-oxide, which contributes to $\sim 90 \%$ of the tPDE4i activity. ${ }^{27,28} \mathrm{ROF}$ $N$-oxide is primarily cleared by the enzyme CYP3A4, and a number of covariates can affect the activity. ${ }^{29,30} \mathrm{PK}$ analyses found that patients who discontinued ROF $500 \mu \mathrm{g}$ daily in the main 12-week trial of OPTIMIZE because of side effects of interest had a slightly higher median tPDE4i than those able to tolerate this dose. It is plausible that higher tPDE4i levels lead to more potential off-target effects of ROF such as nausea and diarrhea. However, as expected with linear PK, reducing the dose to $250 \mu \mathrm{g}$ daily in these patients reduced tPDE4i to well below that typically observed in patients able to tolerate $500 \mu \mathrm{g}$ daily. However, a daily dose of $250 \mu \mathrm{g}$ should not be considered suitable as a therapeutic maintenance dose, as efficacy in exacerbation reduction has not been adequately demonstrated in clinical studies.

A recent Korean study retrospectively analyzed data from 85 patients with severe/very severe COPD taking either $500 \mu \mathrm{g}$ or $250 \mu \mathrm{g}$ ROF daily, up-titrated to $500 \mu \mathrm{g}$ daily up to 3 months after. There was a trend toward fewer AEs and discontinuations with the reduced initial dose. ${ }^{31}$ Similarly, a recent PK modeling analysis ${ }^{13}$ predicted that ROF $250 \mu \mathrm{g}$ daily and $500 \mu \mathrm{g}$ on alternate days were associated with lower plasma drug concentrations, lower tPDE4i, and lower incidence of diarrhea, nausea, and headache compared with ROF $500 \mu \mathrm{g}$ daily. These data support the findings of the OPTIMIZE study.

Limitations of the current study include the lack of a placebo arm, the low sample size in the down-titration phase, and a short study duration of 12 weeks compared with a long-term maintenance treatment. Nonetheless, the study population is one of the largest to investigate side effects in a targeted COPD population, and gives us confidence in the validity of our conclusions. 


\section{Conclusion}

Starting ROF treatment at $250 \mu \mathrm{g}$ daily for 4 weeks before increasing to the therapeutic maintenance dose of $500 \mu \mathrm{g}$ daily reduced treatment discontinuations and improved the tolerability profile compared with initiating treatment at $500 \mu \mathrm{g}$ daily. In practice, this should help patients with COPD to stay longer on treatment with the therapeutic dose. However, use of $250 \mu \mathrm{g}$ OD as long-term maintenance therapy may not induce sufficient PDE4 inhibition to exert clinical efficacy.

\section{Acknowledgments}

Ken Nip (Takeda) provided additional statistical assistance, and Udo-Michael Goehring provided study interpretation. Ella Palmer, PhD (Synergy Vision, London, UK, supported by AstraZeneca) provided writing and editorial assistance with the preparation of this manuscript, in accordance with Good Publication Practice (GPP3) guidelines (http:// www.ismpp.org/gpp3). This study was funded by Takeda Pharmaceutical Company and AstraZeneca. Data from the OPTIMIZE study were presented as an abstract (PA308) at the European Respiratory Society International Congress, 3-7 September 2016, London, UK. Additionally, the pharmacokinetic and pharmacodynamics data from this study were presented as an abstract (A1337) at the American Thoracic Society 2017 International Conference, 19-14 May 2017, Washington DC, USA.

\section{Disclosure}

NB was employed by Takeda Development Centre Europe Ltd, London, UK. The authors report no other conflicts of interest in this work.

\section{References}

1. Mullerova H, Maselli DJ, Locantore N, et al. Hospitalized exacerbations of COPD: risk factors and outcomes in the ECLIPSE cohort. Chest. 2015;147(4):999-1007.

2. Soler-Cataluna J, Martinez-Garcia M, Roman Sánchez P, Salcedo E, Navarro M, Ochando R. Severe acute exacerbations and mortality in patients with chronic obstructive pulmonary disease. Thorax. 2005; 60(11):925-931.

3. Hartl S, Lopez-Campos JL, Pozo-Rodriguez F, et al. Risk of death and readmission of hospital-admitted COPD exacerbations: European COPD Audit. Eur Respir J. 2016;47(1):113-121.

4. Wedzicha JA, Calverley PM, Rabe KF. Roflumilast: a review of its use in the treatment of COPD. Int J Chron Obstruct Pulmon Dis. 2016;11: 81-90.

5. Bateman ED, Rabe KF, Calverley PM, et al. Roflumilast with longacting \{beta 2 agonists for COPD: influence of exacerbation history. Eur Respir J. 2011;38(3):553-560.

6. Calverley PM, Rabe KF, Goehring UM, et al; M2-124 and M2-125 Study Groups. Roflumilast in symptomatic chronic obstructive pulmonary disease: two randomised clinical trials. Lancet. 2009;374(9691):685-694.
7. Martinez FJ, Calverley PM, Goehring UM, Brose M, Fabbri LM, Rabe KF. Effect of roflumilast on exacerbations in patients with severe chronic obstructive pulmonary disease uncontrolled by combination therapy (REACT): a multicentre randomised controlled trial. Lancet. 2015;385(9971):857-866.

8. Rabe KF, Calverley PMA, Martinez FJ, Fabbri LM. Effect of roflumilast in patients with severe COPD and a history of hospitalisation. Eur Respir J. 2017;50(1):1700158.

9. Fabbri LM, Calverley PM, Izquierdo-Alonso JL, et al. Roflumilast in moderate-to-severe chronic obstructive pulmonary disease treated with longacting bronchodilators: two randomised clinical trials. Lancet 2009;374(9691):695-703.

10. Calverley PM, Martinez FJ, Fabbri LM, Goehring UM, Rabe KF. Does roflumilast decrease exacerbations in severe COPD patients not controlled by inhaled combination therapy? The REACT study protocol. Int J Chron Obstruct Pulmon Dis. 2012;7:375-382

11. Martinez FJ, Rabe KF, Sethi S, et al. Effect of roflumilast and inhaled corticosteroid/long-acting beta2-agonist on chronic obstructive pulmonary disease exacerbations (RE(2)SPOND). A randomized clinical trial. Am J Respir Crit Care Med. 2016;194(5):559-567.

12. Munoz-Esquerre M, Diez-Ferrer M, Monton C, et al. Roflumilast added to triple therapy in patients with severe COPD: a real life study. Pulm Pharmacol Ther. 2015;30:16-21.

13. Lahu G, Facius A. Application of population pharmacokinetic modeling to explore the impact of alternative roflumilast dosing regimens on tolerability. Int J Clin Pharmacol Ther. 2013;51(11):832-836.

14. Rabe KF. Roflumilast for the treatment of chronic obstructive pulmonary disease. Expert Rev Respir Med. 2010;4(5):543-555.

15. Rabe KF. Update on roflumilast, a phosphodiesterase 4 inhibitor for the treatment of chronic obstructive pulmonary disease. Br J Pharmacol. 2011;163(1):53-67.

16. Lahu G, Hunnemeyer A, Diletti E, et al. Population pharmacokinetic modelling of roflumilast and roflumilast N-oxide by total phosphodiesterase-4 inhibitory activity and development of a population pharmacodynamicadverse event model. Clin Pharmacokinet. 2010;49(9):589-606.

17. Facius A, Bagul N, Gardiner P, Watz H. Pharmacokinetics of a 4-week up-titration regimen of roflumilast in the OPTIMIZE study. Am J Respir Crit Care Med. 2017;195:A1337.

18. Zhang J, Yu KF. What's the relative risk? A method of correcting the odds ratio in cohort studies of common outcomes. JAMA. 1998; 280(19):1690-1691.

19. Leung LK, Patafio FM, Rosser WW. Gastrointestinal adverse effects of varenicline at maintenance dose: a meta-analysis. BMC Clin Pharmacol. 2011;11:15.

20. Drugs.com [webpage on the Internet]. Varenicline Tablets (Dosage) Summary of Product Characteristics (SPC) - (FDA). 2016. [updated March 2, 2017]. Available from: https://www.drugs.com/dosage/ varenicline.html. Accessed March 29, 2017.

21. Medicines.org.uk [webpage on the Internet]. Vargatef $100 \mathrm{mg}$ and $150 \mathrm{mg}$ Soft Capsules - Summary of Product Characteristics (SPC) (eMC). 2016. [updated March 9, 2017]. Available from: https://www. medicines.org.uk/emc/medicine/29790. Accessed March 29, 2017.

22. Medicines.org.uk [webpage on the Internet]. Esbriet $267 \mathrm{mg}$ Hard Capsules-Summary of Product Characteristics (SPC) - (eMC). 2015 [updated August 5, 2016]. Available from: https://www.medicines.org. uk/emc/medicine/29932. Accessed March 29, 2017.

23. Spina D. PDE4 inhibitors: current status. Br J Pharmacol. 2008; 155(3):308-315

24. Akabas MH. Cystic fibrosis transmembrane conductance regulator. Structure and function of an epithelial chloride channel. J Biol Chem. 2000;275(6):3729-3732.

25. Blanchard E, Zlock L, Lao A, et al. Anchored PDE4 regulates chloride conductance in wild-type and DeltaF508-CFTR human airway epithelia FASEB J. 2014;28(2):791-801.

26. Boswell-Smith V, Cazzola M, Page CP. Are phosphodiesterase 4 inhibitors just more theophylline? J Allergy Clin Immunol. 2006; 117(6):1237-1243. 
27. Hatzelmann A, Schudt C. Anti-inflammatory and immunomodulatory potential of the novel PDE4 inhibitor roflumilast in vitro. J Pharmacol Exp Ther. 2001;297(1):267-279.

28. Hauns B, Hermann R, Hunnemeyer A, et al. Investigation of a potential food effect on the pharmacokinetics of roflumilast, an oral, once-daily phosphodiesterase 4 inhibitor, in healthy subjects. J Clin Pharmacol. 2006;46(10):1146-1153.

29. Bebia Z, Buch SC, Wilson JW, et al. Bioequivalence revisited: influence of age and sex on CYP enzymes. Clin Pharmacol Ther. 2004; 76(6):618-627.
30. Mangoni AA, Jackson SH. Age-related changes in pharmacokinetics and pharmacodynamics: basic principles and practical applications. Br J Clin Pharmacol. 2004;57(1):6-14.

31. Hwang H, Shin JY, Park KR, et al. Effect of a dose-escalation regimen for improving adherence to roflumilast in patients with chronic obstructive pulmonary disease. Tuberc Respir Dis (Seoul). 2015;78(4): $321-325$.

\section{Publish your work in this journal}

The International Journal of COPD is an international, peer-reviewed journal of therapeutics and pharmacology focusing on concise rapid reporting of clinical studies and reviews in COPD. Special focus is given to the pathophysiological processes underlying the disease, intervention programs, patient focused education, and self management protocols.

\section{Dovepress}

This journal is indexed on PubMed Central, MedLine and CAS. The manuscript management system is completely online and includes a very quick and fair peer-review system, which is all easy to use. Visit http://www.dovepress.com/testimonials.php to read real quotes from published authors.

Submit your manuscript here: http://www.dovepress.com/international-journal-of-chronic-obstructive-pulmonary-disease-journal 